Check for updates

Cite this: RSC Adv., 2017, 7, 42430

Received 20th July 2017

Accepted 14th August 2017

DOI: $10.1039 / c 7 r a 07984 b$

rsc.li/rsc-advances

\section{Hierarchical nitrogen-doped porous carbon derived from lecithin for high-performance supercapacitors}

\begin{abstract}
Muslum Demir, (D) Sushil Kumar Saraswat and Ram B. Gupta*
The development of renewable carbon sources for sustainable energy storage applications is of significance importance. Herein, we report the synthesis of three-dimensional $\mathrm{N}$-doped carbons derived from lecithin via a simple route. Hierarchical porous carbons with high surface area (up to $1803 \mathrm{~m}^{2} \mathrm{~g}^{-1}$ ) and nitrogendoping level (up to 9.2 wt\%) were successfully prepared by hydrothermal carbonization and a subsequent thermal annealing. The electrochemical performance of the carbon electrodes was examined with both two and three-electrode cell configurations in $1 \mathrm{M} \mathrm{KOH}$ and $1 \mathrm{M} \mathrm{H}_{2} \mathrm{SO}_{4}$ electrolytes. The as-prepared NC-800 electrode features a large specific capacitance (285 $\mathrm{F} \mathrm{g}^{-1}$ at $0.5 \mathrm{~A} \mathrm{~g}^{-1}$ ), high-rate capacitive behavior, and long-term cycling stability ( $8 \%$ loss after 20000 cycles). Furthermore, $\mathrm{NC}-800$ exhibits an energy density of $24.7 \mathrm{~W} \mathrm{~h} \mathrm{~kg}^{-1}$ at a power density of $500 \mathrm{~W} \mathrm{~kg}^{-1}$ in $1 \mathrm{M} \mathrm{H}_{2} \mathrm{SO}_{4}$. The excellent electrochemical performance of $\mathrm{N}$-doped carbons is attributed to the unique hierarchical porous frameworks along with pseudocapacitive effect. This work opens up a new approach for preparation of hierarchical $\mathrm{N}$-doped porous carbon materials with tailored properties for supercapacitor applications.
\end{abstract}

\section{Introduction}

Electrochemical supercapacitors (ESs), also known as electrodouble layer capacitors have received much attention due to their high power density, fast charge-discharge rate, and long cyclability. ${ }^{1-3}$ ESs have been extensively implemented in a variety of applications such as electronic devices, hybrid electric vehicles, memory backup, etc. ${ }^{4}$ ESs can be classified into two types based on their charge storage mechanism: (a) electric double layer capacitor (EDLC) in which energy is stored by adsorption of ions on the electrode surface and (b) pseudocapacitor (also known as faradaic supercapacitor) in which charge is stored through redox reactions on the electrode material. ${ }^{5}$

The electrode material plays a key role in determining the capacitance of a supercapacitor. To date, porous activated carbons (PACs), ${ }^{5,6}$ metal oxides, ${ }^{7}$ conductive polymers, ${ }^{8}$ graphene ${ }^{9}$ and carbon nanotubes ${ }^{\mathbf{1 0}}$ have been utilized as potential electrode materials in energy storage technologies. ${ }^{\mathbf{1 1 , 1 2}}$ Among these, abundant PACs present high surface area, excellent stability, and moderate cost. However, pristine (or bare) PACs suffer from low electron/ion conductivity, lacking of pseudocapacitance contribution but also their mediocre electrochemical performance lead to a poor energy/power density. In order to

Department of Chemical \& Life Science Engineering, Virginia Commonwealth University, Richmond, VA 23284, USA.E-mail: demirm@vcu.edu; rbgupta@vcu.edu; Tel: +1-(804)-828-1211 overcome these issues, pristine PACs have been modified by introducing heteroatoms (such as N, S, P) into their framework to further enhance the electrochemical activity, surface wettability, and electron/electrolyte conductivity through the pseudocapacitive contribution. ${ }^{\mathbf{1 3 - 1 5}}$ The induced electrochemical activity may arise from shifting of the conjugation electrons between heteroatom (lone-pair) and carbon framework, which causes facilitation of electron transfer. ${ }^{\mathbf{1 6}}$ Moreover, the high surface area of PACs is mostly due to their overwhelmingly microporous structure (i.e., micropore distributions ranging from 0.5 to $1.1 \mathrm{~nm}$ ). These narrow pores do not allow adequate transport of ions which greatly hinder practical applications of PACs as high energy/power density supercapacitors. ${ }^{17-19}$ Therefore, it is essential to develop hierarchical porous architectures with abundant micropores (to accumulate charge effectively), interconnected mesopores (to reduce the ion diffusion distance) and appropriate macropores (to serve as the ionbuffering reservoirs for storing electrolyte ions). ${ }^{20-22}$ In the last decade, many template-based methods such as using silica oxides or metallic compound have been reported for synthesizing of hierarchical porous carbons. ${ }^{2,24}$ However, these methods could not be commercialized due to the consumption of high-cost templates and multistep synthesis process. Thus, it is vital to develop a simple and inexpensive method for fabricating of hierarchical porous carbon. In this work, we utilized a straightforward chemical activation (with $\mathrm{KOH}$ ) approach which yields a 3D hierarchical porous structures. The successful formation of hierarchical porous carbon using $\mathrm{KOH}$ activation 
approach has been well-studied previously by Qie, ${ }^{25}$ Fang $^{6}$ and Wei ${ }^{26}$ et al.

With the depletion of fossil fuels and increasing environmental pollution, there is a great demand to develop electrode materials derived from the renewable, eco-friendly and low-cost resources such as biomass and their derivatives. So far, the efforts have been devoted to carbon electrode materials originated from willow catkins,${ }^{27}$ pine cone,${ }^{28}$ lignin,${ }^{29-31}$ fungi,${ }^{32}$ and wood sawdust. ${ }^{33}$ In this work, we examine the utilization of lecithin, an agricultural byproduct which is readily available with high purity. Lecithin is a mixture of phosphatides produced from a vegetable source such as soybean or an animal source such as eggs, ${ }^{34,35}$ and is currently used as a natural surfactant in the food, cosmetics, food emulsions and paints industries. ${ }^{34}$ Since the annual supply of lecithin is in great excess, it is desirable to find the alternative applications for lecithin.

In this paper, we develop a facile and low-cost strategy to produce hierarchical $\mathrm{N}$-doped porous carbons from lecithin as carbon precursor. Our proposed synthetic strategy focuses on (i) utilizing the low-cost resources, (ii) creating high surface area along with hierarchical porous networks, and (iii) enhancing electrochemical performance. The electrochemical performance will be examined with two and three-electrode cell configurations in both acidic and basic electrolytes.

\section{Experimental}

\subsection{Chemicals}

Soybean lecithin was received from Stakich Inc. (Bloomfield Hills, MI). The potassium hydroxide ( $\mathrm{KOH})$ and polytetrafluoroethylene (PTFE, $60 \mathrm{wt} \%$ dispersion in $\mathrm{H}_{2} \mathrm{O}$ ) were obtained from Sigma-Aldrich. Carbon black was received from Alfa Aesar. Ni foam was received from MTI Corporation. Chemicals were used as received unless mentioned in the text. Water $(18.2 \mathrm{M} \Omega \mathrm{cm})$ was used as a solvent in the hydrothermal treatments.

\subsection{Synthesis of bio-char from lecithin}

Bio-char was prepared by hydrothermal carbonization (HTC) of lecithin using in situ ultra-sonication. In a typical synthesis, $10 \mathrm{~g}$ of lecithin was mixed with deionized water $(80 \mathrm{~mL})$ into sonicated Col-Int reactor. The temperature and pressure of the reactor were maintained at $300{ }^{\circ} \mathrm{C}$ and $100 \mathrm{bar}$, respectively, for $30 \mathrm{~min}$ reaction time. ${ }^{30}$ The reactor was cooled to room temperature and the resultant bio-char was isolated by filtration.

\subsection{Synthesis of $\mathbf{N}$-doped $3 \mathrm{D}$ hierarchically porous carbon}

N-Doped 3D hierarchically porous carbon was synthesized by thermal annealing of bio-char in the presence of $\mathrm{KOH}$ (surface activating agent) and urea (a nitrogen source). In a typical procedure, $3.32 \mathrm{~g} \mathrm{KOH}$ was dissolved in $20 \mathrm{~mL}$ deionized water. Then, urea (6.64 g) and bio-char (3.32 g) were added to the $\mathrm{KOH}$ aqueous solution and stirred for $30 \mathrm{~min}$. The reaction mixture was transferred into an $80 \mathrm{~mL}$ Teflon-lined stainless autoclave and then heated to $90{ }^{\circ} \mathrm{C}$ for $10 \mathrm{~h}$. The obtained brown product was filtered and dried at $80^{\circ} \mathrm{C}$ overnight. The dried sample was heated to a given temperature 700,800 , or $900{ }^{\circ} \mathrm{C}$ at a heating rate of $5{ }^{\circ} \mathrm{C} \min ^{-1}$ for $1 \mathrm{~h}$ under $\mathrm{N}_{2}$ flow in a Carbolite (MTF250) tubular furnace.

\subsection{Physical characterization}

FT-IR spectra of samples were obtained by using a Smart ATR Nicolet Nexus 670 FT-IR spectrometer. A sample was placed directly on a diamond tip and spectra collected from averaging with operating 16 scans with a resolution of $4 \mathrm{~cm}^{-1}$ scanned from 4000 to $400 \mathrm{~cm}^{-1}$. The extent of graphitization was examined by Raman spectroscopy (Horiba LABRam HR; excitation wavelength $=532 \mathrm{~nm}$ ). The Brunauer-Emmett-Teller (BET) specific surface area and pore size distributions were obtained from an Autosorb iQ2 (Qantachrome) surface analyzer. Pore size distribution maxima was calculated using $\mathrm{N}_{2}$ isotherm at $77 \mathrm{~K}$ on carbon model (slit/cylindrical pores and QSDFT method using adsorption branch). The micro pore volume was determined by cumulative pore volume at $2 \mathrm{~nm}$ maxima of the PSD assuming slit/cylindrical shaped pores and QSDFT model. Total pore volume was measured at $P / P_{0}$ equal 0.95 . Thermal stability test of the synthesized materials was performed using a Perkin thermo-gravimetric analyzer. Operating conditions were fixed to a constant heating rate of $5{ }^{\circ} \mathrm{C} \mathrm{min}{ }^{-1}$ with the $\mathrm{N}_{2}$ flow (ranging from $20{ }^{\circ} \mathrm{C}$ to $1000{ }^{\circ} \mathrm{C}$ ). Scanning electron microscope (SEM) (Hitachi SU-70 FE-SEM) images were obtained at $5 \mathrm{kV}$ to examine the morphology of the materials. X-ray photoelectron spectroscopy (ESCAlab 250) was conducted in order to examine the chemical composition $(\mathrm{C}, \mathrm{O}, \mathrm{N})$ and nature of the functionalized groups on the surface of the prepared materials.

\subsection{Electrode preparation and electrochemical measurement}

The working electrodes were fabricated from a mixture of $80 \mathrm{wt} \%$ active electrode material, $10 \mathrm{wt} \%$ carbon black and $10 \mathrm{wt} \%$ binder (PTFE) in ethanol solution. The viscous slurry was casted onto a current collector (nickel foam, $1.5 \mathrm{~cm} \times 3 \mathrm{~cm}$ ) and dried at $80^{\circ} \mathrm{C}$ for $12 \mathrm{~h}$ in vacuum. In order to achieve a good electronic contact, dried electrode was uniaxially pressed at 5 tons. The geometric exposed surface area of the prepared electrode was $0.32 \mathrm{~cm}^{2}$. The amount of active material and thickness of electrode were about $1.6 \mathrm{mg}$ and $45 \mu \mathrm{m}$ so that the calculated densities of electrode films are about $1.15 \mathrm{~g} \mathrm{~cm}^{-3}$. In a three-electrode cell configuration, as-prepared electrodes operated as a working electrode, $\mathrm{Pt}$ wire as auxiliary electrode and $\mathrm{Ag} / \mathrm{AgCl}(1 \mathrm{M} \mathrm{KCl}$ solution) applied to reference electrodes in $1 \mathrm{M} \mathrm{KOH}$ electrolyte within the potential range of -1.0 to $0.0 \mathrm{~V}$ on a $\mathrm{CHI} 660 \mathrm{E}$ electrochemical workstation (CH Instruments Inc.) at room temperature. Additionally, a twoelectrode cell testing was conducted in a 2025 coin cell with two nearly identical electrodes and Fisher brand (P8) filter paper as a separator. $1 \mathrm{M} \mathrm{KOH}$ and $1 \mathrm{M} \mathrm{H}_{2} \mathrm{SO}_{4}$ aqueous solutions were examined as electrolytes, within the potential range of 0 to $1.0 \mathrm{~V}$. The EIS data were collected in the frequency range of $0.01 \mathrm{~Hz}$ to $500 \mathrm{kHz}$ with a $5 \mathrm{mV}$ AC amplitude.

The gravimetric specific capacitance $\left(C_{\mathrm{s}}, \mathrm{F} \mathrm{g}^{-1}\right)$ of the electrodes was calculated from the galvanostatic charge-discharge (GCD) curves according to the eqn (1) and (2): 


$$
\begin{aligned}
C_{\mathrm{s}} & =\frac{I \Delta t}{m \Delta V}(\text { three-electrode cell }) \\
C_{\mathrm{s}} & =\frac{2 I \Delta t}{m \Delta V}(\text { two-electrode cell })
\end{aligned}
$$

where $I$ is the discharge current (A), $\Delta V$ is discharging voltage $m$ is the mass of the active electrode material $(\mathrm{g})$ and $\Delta t$ is the discharge time. ${ }^{36}$

The volumetric specific capacitance $\left(C_{\mathrm{v}}, \mathrm{F} \mathrm{cm}^{-3}\right)$ was calculated by following equation: ${ }^{37}$

$$
C_{\mathrm{v}}=\rho C_{\mathrm{s}}
$$

where $C_{\mathrm{S}}$ is specific capacitance, $\rho\left(\mathrm{g} \mathrm{cm}^{-3}\right)$ is the packing density calculated by eqn $(4)^{38}$

$$
\rho=\frac{\alpha m}{l A}
$$

where $m$ is amount of total material, $\alpha$ is the weight fraction of the active material (0.8), $l$ is thickness of electrode and $A$ is geometric area of electrode.

The energy density $\left(E, \mathrm{~W} \mathrm{~h} \mathrm{~kg}{ }^{-1}\right)$ and the power density $\left(P, \mathrm{~W} \mathrm{~kg}{ }^{-1}\right)$ of a supercapacitor in two cell-electrode configurations obtained by the following equations:

$$
\begin{gathered}
E=\frac{1}{2} C_{\mathrm{s}} \Delta V^{2} \\
P=\frac{E}{\Delta t}
\end{gathered}
$$

\section{Results and discussion}

The schematic synthesis pathway of $\mathrm{N}$-doped carbons derived from soy lecithin via a two-step process is shown in Fig. 1. First, soy lecithin was converted into bio-char via hydrothermal carbonization (HTC) using the in situ ultra-sonication reactor. In the second step, the bio-char was treated with urea and $\mathrm{KOH}$ and then transformed to N-doped porous carbons via thermal annealing. In this process, soy lecithin and urea were consumed as carbon and nitrogen sources while $\mathrm{KOH}$ was used as a pore forming agent. The carbons were labeled as NC- $x$, where $\mathrm{N}$ and $\mathrm{C}$ denote the nitrogen and carbon, respectively and $x$ refers to the carbonization temperature in ${ }^{\circ} \mathrm{C}$. For comparison, a pristine lecithin-derived carbon (C-800) was processed in the same manner but without the use of nitrogen source. We like to note that our utilization of lecithin as precursor, without further purification, is a sustainable method for the "green" production of carbon materials. The environmentally-benign hydrothermal carbonization together with relatively mild annealing process and lack of toxic byproducts, offer a clean and easy way for the production of nitrogen-doped porous carbons.

\subsection{Physical properties}

The scanning electron micrographs of NC-700, NC-800, NC-900 and C-800 are shown in Fig. 2a-e. Regardless of the annealing temperature, N-doped carbons showed irregular 3D morphology

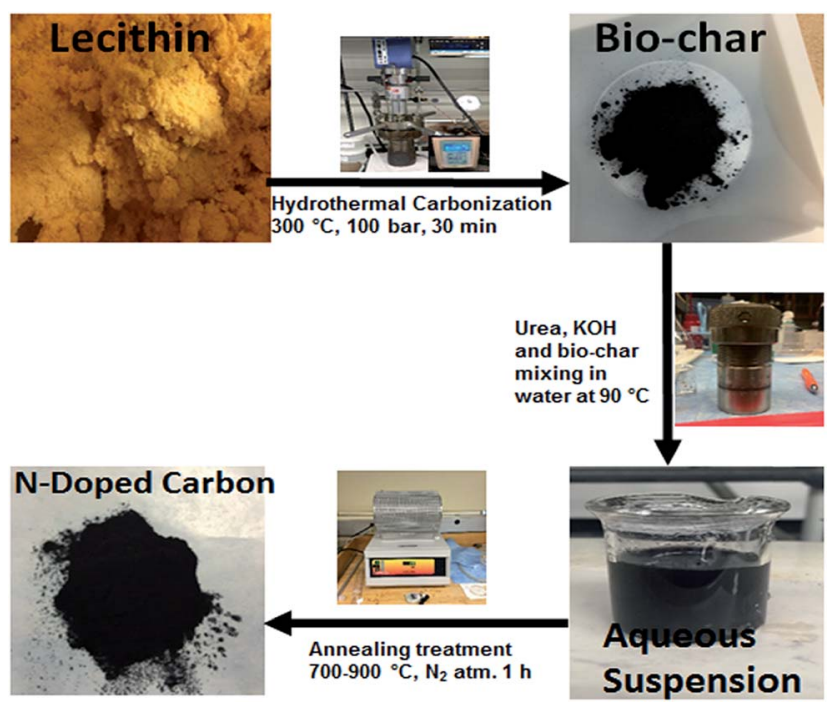

Fig. 1 Schematic illustration for synthesis of hierarchical N-doped porous carbons.

with various sizes. It is important to see that an abundant macropore channel structure exists in NC-800 sample at high magnification, which may be attributed to the $\mathrm{KOH}$ etching process. ${ }^{39}$ As shown in Fig. $2 \mathrm{f}-\mathrm{h}$, energy-dispersive X-ray spectroscopy (EDX) elemental mapping of NC-800 reveals a homogeneous distribution of $\mathrm{C}, \mathrm{N}$, and $\mathrm{O}$ elements in the structure.

The thermogravimetric analyses of lecithin and biochar are shown in Fig. 3a. The small initial weight loss from room temperature to $150{ }^{\circ} \mathrm{C}$ is due to the physical adsorption of water in both the samples. The decomposition of lecithin and biochar started at around $200{ }^{\circ} \mathrm{C}$ and continued till $500{ }^{\circ} \mathrm{C}$. The residual mass content of the lecithin and bio-char was found to be 17.1 and $27 \mathrm{wt} \%$, respectively. FT-IR spectra of bio-char, NC800 , C-800, as well as lecithin, are shown in Fig. 3b. Vibrational peaks located between 3200 and $3600 \mathrm{~cm}^{-1}$ correspond to $-\mathrm{OH}$ stretching band, between 3010-2855 $\mathrm{cm}^{-1}$ correspond to aliphatic $-\mathrm{CH}$ and stretching of carbonyl groups fatty acids $\mathrm{C}-\mathrm{C}=\mathrm{O}$ identified in the IR spectrum of lecithin appears at $1738 \mathrm{~cm}^{-1}$. Additionally, the peaks located at 1217 and $1061 \mathrm{~cm}^{-1}$ assigns to phosphate functional groups, are characteristic peaks for lecithin. ${ }^{40}$ The vibrations of the oxygen and phosphate functional groups such as $\mathrm{C}-\mathrm{C}=\mathrm{O}, \mathrm{O}=\mathrm{P}-\mathrm{O}$, obtained from lecithin and biochar, disappeared after thermal annealing. It is worthwhile noting that $\mathrm{C}-\mathrm{N}$ functional group could not be detected due to the their low intensity or small amount of $\mathrm{C}-\mathrm{N}$ functional groups.

Raman spectroscopy is conducted to probe graphitization of $\mathrm{N}$-doped carbons (Fig. 3c). The D-band located at $1346 \mathrm{~cm}^{-1}$ corresponds to amorphous $\mathrm{sp}^{3}$ hybridized carbon while the G-band at $1587 \mathrm{~cm}^{-1}$ refers to the presence of a well-ordered $\mathrm{sp}^{2}$ hybridized graphite structure. The intensity ratio of the $\mathrm{D}$ band to the $\mathrm{G}$ band $\left(R=I_{\mathrm{D}} / I_{\mathrm{G}}\right)$ reflects the graphitization degree. ${ }^{41,42}$ In the present study, the intensity ratio $(R)$ was found to be 1.01, 0.98, 1.02 and 0.91 for NC-700, NC-800, NC-900 and, C-800, respectively, indicating that the highest degree of graphitization arises at $800{ }^{\circ} \mathrm{C}$ annealing temperature. It is worth noting 

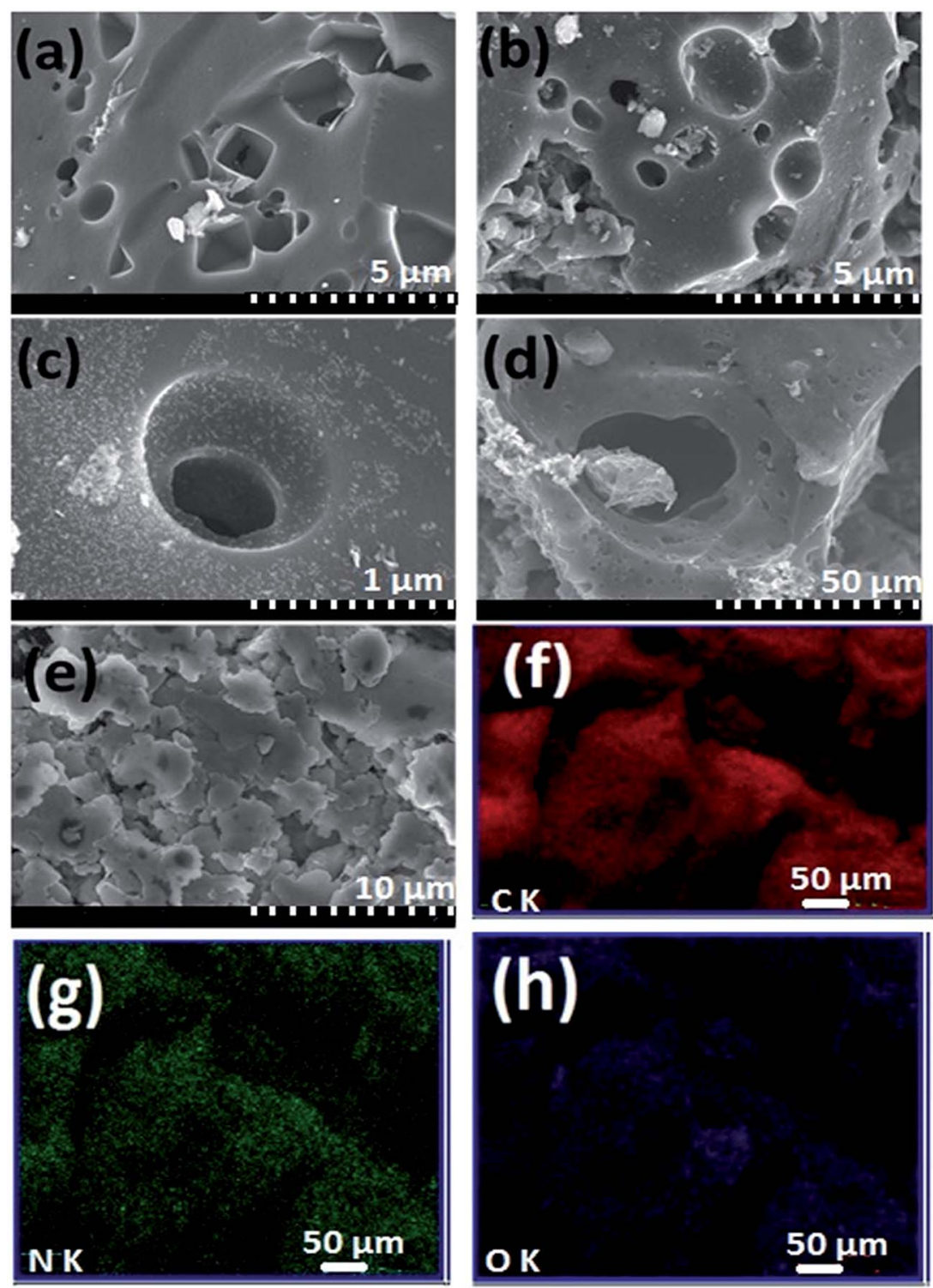

Fig. 2 SEM images of (a) NC-700, (b and c) NC-800, (d) NC-900, and (e) C-800 carbons. Elemental mappings of NC-800: (f) carbon, (g) nitrogen, (h) oxygen.

that the abundant defect sites on the carbon frameworks were observed at $900{ }^{\circ} \mathrm{C}$ caused by $\mathrm{KOH}$ etching process and decomposing of $\mathrm{N}$ and $\mathrm{O}$ functional groups at high temperature. $^{\mathbf{4 1}}$

$\mathrm{KOH}$ surface activation used here follows a typical reaction mechanism, ${ }^{43}$

$$
\begin{aligned}
& =\mathrm{CH}_{2}+4 \mathrm{KOH} \rightarrow \mathrm{K}_{2} \mathrm{CO}_{3}+\mathrm{K}_{2} \mathrm{O} \ldots \\
& 2 \mathrm{C}+6 \mathrm{KOH} \rightarrow 2 \mathrm{~K}+3 \mathrm{H}_{2} 2 \mathrm{~K}_{2} \mathrm{CO}_{3} \ldots
\end{aligned}
$$

where the production of $\mathrm{CO}_{2}$ from the decomposition of $\mathrm{K}_{2} \mathrm{CO}_{3}$ contributes to the porosity formation via carbon gasification. Additionally, the reaction of potassium compounds $\left(\mathrm{K} / \mathrm{K}_{2} \mathrm{CO}_{3}\right)$ $\mathrm{K}_{2} \mathrm{O}$ ) with carbon leads to decomposing of graphite sheets in the carbon matrix, ${ }^{\mathbf{4}}$ forming amorphous carbon at elevated temperatures, which is consistent with the Raman analysis.
Nitrogen sorption measurements were carried out to investigate the porosity of carbons. The BET equation was applied to the $\mathrm{N}_{2}$ adsorption isotherms for obtaining the surface area where the $P / P_{0}$ range was chosen by micropore BET assistant software to yield a high $R_{2}$ value and a positive line intersect of multipoint BET fitting. In general, $\mathrm{N}_{2}$ adsorption isotherms exhibit a combination of type I and type IV characteristics (Fig. 3d). A steep increase of $\mathrm{N}_{2}$ uptake at a relatively low pressure indicates the presence of mostly micropores while the broadening of the knee in the medium pressure range is a sign of introducing narrow mesopores into the system. ${ }^{45}$ The BET surface areas were found to be 1264, 1803, 2695 and $1438 \mathrm{~m}^{2} \mathrm{~g}^{-1}$ for NC-700, NC-800, NC-900 and C-900, respectively (Table 1). Micro and total (in parenthesis) pore volumes were $0.4(0.56)$, 0.57 (0.8), $0.61(01.2)$ and $0.44(0.82) \mathrm{cm}^{3} \mathrm{~g}^{-1}$ for NC-700, NC800 , NC-900 and C-900, respectively. It is worth mentioning 

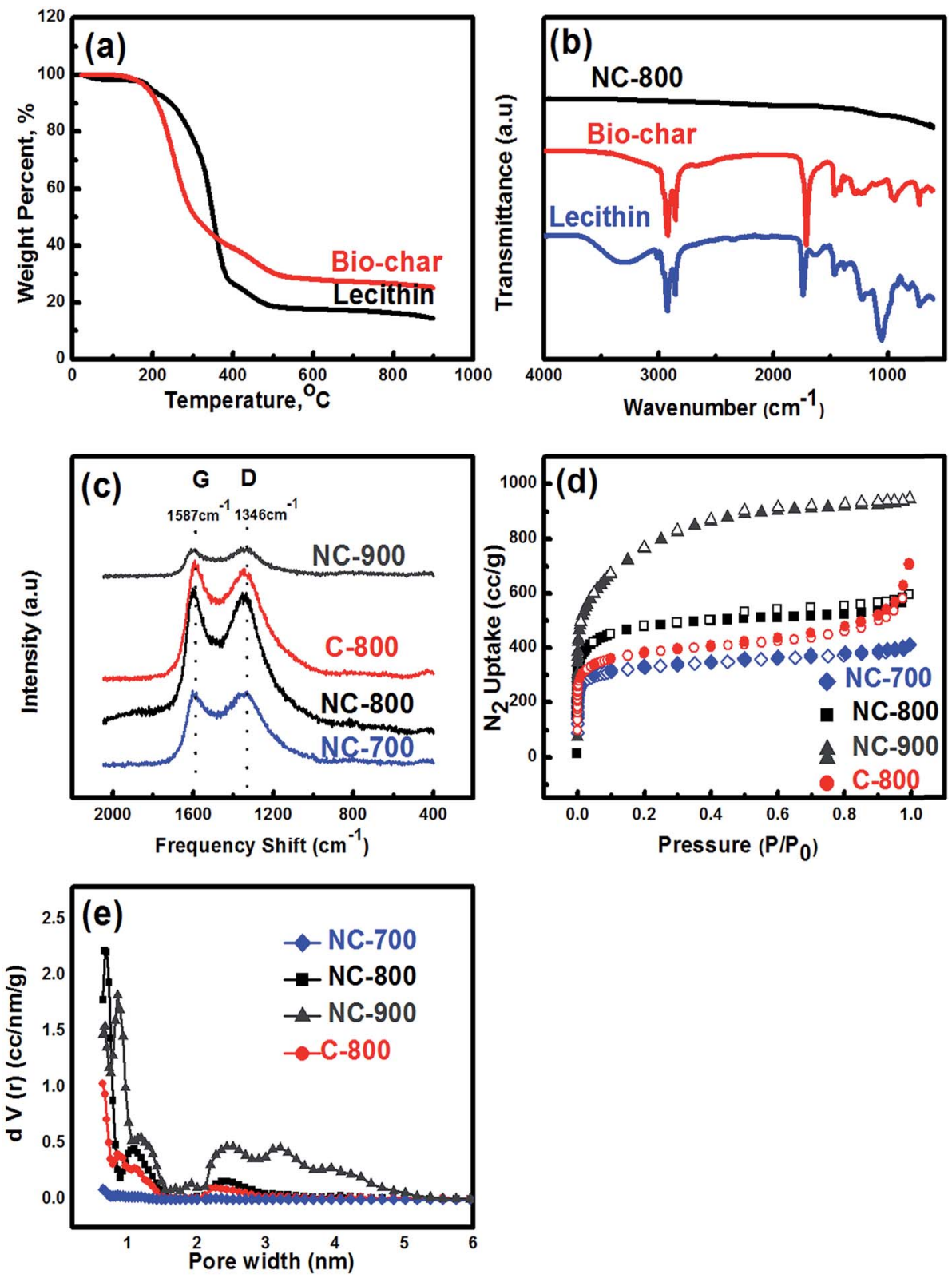

Fig. 3 (a) TGA curves of lecithin and bio-char, (b) FTIR spectra of lecithin, bio-char and NC-800, (c) Raman spectra of N-doped carbons, (d) N2 isotherms of samples at $77 \mathrm{~K}$, and (e) pore size distributions curves derived from $\mathrm{N}_{2}$ isotherms.

that the BET surface area, pore size distribution, and pore volume of the as-prepared carbons strongly depend on the annealing temperature. At a relatively low temperature of $700{ }^{\circ} \mathrm{C}$, the wide micropores $(>1 \mathrm{~nm})$ or any mesopores could not develop properly due to insufficient $\mathrm{KOH}$ etching effect. ${ }^{46}$ Increasing annealing temperature facilates the formation of micro/meso structure due to the enhanced $\mathrm{KOH}$ etching. The surface area and ratio of micro to total pore volume of NC-800 were approximately $20 \%$ higher than pristine (C-800), which is caused by the volatilization of nitrogen-containing groups as defects at early stages of annealing and leads to micro/ mesopore structure formation. ${ }^{47}$ The pore size distribution of samples indicates the presence of micropore and mesopore ranging from 0.8 to $3.2 \mathrm{~nm}$ as shown in Fig. 3e and summarized in Table 1. Such a hierarchically porous structure along with high surface area is highly desirable for high capacitance, ion transportation, and charge accumulation. ${ }^{48}$

The surface chemical composition of samples was investigated by XPS as shown in Fig. 4a. The carbon content of carbons was found to be $75.3,77.8,79$ and 82.5 at $\%$ for NC-700, NC-800, NC-900 and C-800, respectively, as shown in Table 2. A higher carbon content at elevated annealing temperatures is due to the deoxygenation or releasing of high volatility nitrogen functional groups. The nitrogen content is 9.2, 6.5 and 3.4 at\% in NC-700, NC-800 and NC-900, respectively. XPS results reflect the successful nitrogen doping in bio-char by using urea. A small amount of nitrogen presented in C-800 (pristine) is due to the inherent nature of lecithin material. The small peak appeared 
Table 1 Physicochemical and electrochemical properties of produced carbons

\begin{tabular}{|c|c|c|c|c|c|c|c|}
\hline \multirow[b]{2}{*}{ Sample } & \multirow[b]{2}{*}{$C_{\mathrm{s}}^{a}\left(\mathrm{~F} \mathrm{~g}^{-1}\right)$} & \multirow[b]{2}{*}{$I_{\mathrm{D}} / I_{\mathrm{G}}$} & \multirow[b]{2}{*}{$\mathrm{N} / \mathrm{C}$ ratio } & \multirow[b]{2}{*}{ BET surface $\operatorname{area}^{b}\left(\mathrm{~m}^{2} \mathrm{~g}^{-1}\right)$} & \multirow[b]{2}{*}{$\operatorname{PSD}^{c}(\mathrm{~nm})$} & \multicolumn{2}{|l|}{ Pore volume } \\
\hline & & & & & & $\operatorname{Micro}^{d}\left(\mathrm{~cm}^{3} \mathrm{~g}^{-1}\right)$ & $\operatorname{Total}^{e}\left(\mathrm{~cm}^{3} \mathrm{~g}^{-1}\right)$ \\
\hline NC-700 & 236 & 1.01 & 0.12 & 1264 & $0.8-2.2$ & $0.4(71)$ & 0.56 \\
\hline NC-800 & 285 & 0.98 & 0.08 & 1803 & $1.1-2.4$ & $0.57(71)$ & 0.8 \\
\hline NC-900 & 263 & 1.02 & 0.04 & 2695 & $1.1-2.5,3.2$ & $0.61(51)$ & 1.2 \\
\hline C-800 & 248 & 0.91 & 0.01 & 1438 & $0.9-2.3$ & $0.44(53)$ & 0.82 \\
\hline
\end{tabular}

${ }^{a}$ Calculated at $0.5 \mathrm{~A} \mathrm{~g}^{-1}$ current density. ${ }^{b}$ Calculated in the partial pressure range which gives the best linear fitting. ${ }^{c}$ Pore size distribution maxima calculated using $\mathrm{N}_{2}$ isotherm at $77 \mathrm{~K}$ on carbon model (slit/cylinder. pores, by using QSDFT method and adsorption branch of $\mathrm{N}_{2}$ isotherms). ${ }^{d}$ Determined by cumulative pore volume at $2 \mathrm{~nm}$ maxima of the PSD assuming slit/cylindrical shaped pores and QSDFT model; the values in parentheses are the percentage of micropores volume relative to total pore volume. ${ }^{e}$ Total pore volume at $P / P_{0}=0.95$.

in the survey plot at $446 \mathrm{eV}$ may be attributed to indium, which is used as a substrate for XPS analysis. A high-resolution deconvolution of $\mathrm{C} \mathrm{sp}^{2}$ peak is shown in Fig. $4 \mathrm{~b}$ with the main peak located at $284.6 \mathrm{eV}$ assigned to $\mathrm{C}=\mathrm{C}$ bonding. The other minor fitted peaks at 285.6 and $286.6 \mathrm{eV}$ correspond to $\mathrm{C}-\mathrm{C} / \mathrm{CH}_{x} / \mathrm{C}=\mathrm{N}$ and $\mathrm{C}-\mathrm{O}$ bonding, respectively. ${ }^{49}$ Core level XPS
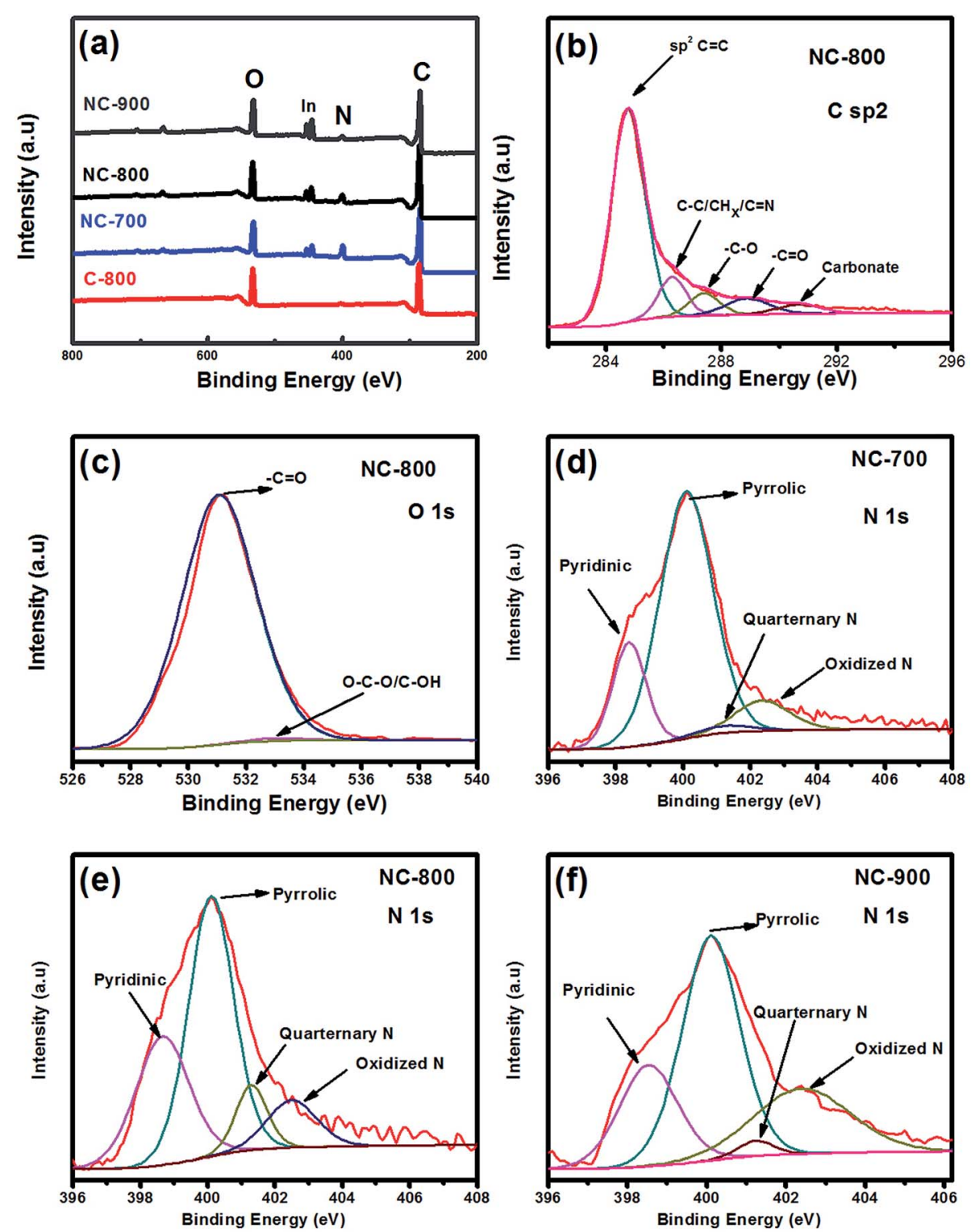

Fig. 4 XPS analyses of produced carbons: (a) survey spectra of NC-700, NC-800 and NC-900, (b) C 1s core level analysis of NC-800, (c) O 1s core level analysis of NC-800, (d) N 1s core level analysis of NC-700, (e) N 1s core level analysis of NC-800, and (f) N 1s core level analysis of NC-900. 
Table 2 Elemental and surface composition of samples ${ }^{a}$

\begin{tabular}{llllllll}
\hline Sample & $\mathrm{C}(\mathrm{wt} \%)$ & $\mathrm{N}(\mathrm{wt} \%)$ & $\mathrm{O}(\mathrm{wt} \%)$ & Pyridinic (at\%) & Pyrrolic (at\%) & Oxidized (at\%) & Quarternary (at\%) \\
\hline NC-700 & 75.3 & 9.2 & 15.5 & 37.7 & 46.9 & 6 & 9.2 \\
NC-800 & 77.8 & 6.5 & 15.8 & 15.1 & 68.4 & 7.3 & 7.2 \\
NC-900 & 79.0 & 3.4 & 17.5 & 16.1 & -10.8 & - & \\
C-800 & 82.5 & 0.6 & 11.9 & - & &
\end{tabular}

scans over smaller energy windows at a high resolution of the $\mathrm{O}$ 1s are presented in Fig. 4c where two types of oxygen functional groups are identified. The main peak located at $531.1 \mathrm{eV}$ refers to $\mathrm{C}=\mathrm{O}$ bond while the small peaks at $532.9 \mathrm{eV}$ correspond to $\mathrm{O}-\mathrm{CO} / \mathrm{C}-\mathrm{OH}$ bonds. The high-resolution deconvolution of the $\mathrm{N}$ 1s spectrum was also used to analyze the nature of the $\mathrm{N}$ atoms/ functionality which revealed four distinct types of nitrogen functionalities: pyridinic-N (398.4 eV), pyrrolic-N (400.1 eV), quarternary-N (401) and oxidized-N (402.5 eV), ${ }^{50,51}$ as shown in Fig. 4d-f. The initial active sites for pseudocapacitive interactions could be facilitated by easily accessible pyridinic/pyrrolic and quarternary nitrogen groups. ${ }^{48}$

\subsection{Electrochemical performance}

The electrochemical performance of the as-prepared electrodes was evaluated using cyclic voltammetry (CV) in $1 \mathrm{M} \mathrm{KOH}$ electrolyte solution and a three-electrode cell configuration. At $20 \mathrm{mV} \mathrm{s}^{-1}$ scan rate, all of the carbon electrodes displayed rectangular-like cyclic voltammograms between -1 to $0.2 \mathrm{~V}$, indicating a nearly perfect capacitive performance (Fig. 5a). The CV curves of carbons with appreciable N-doping feature a slight deviation from perfect rectangular shape and reveal a slight bump within -0.7 to $-0.2 \mathrm{~V}$. This is because of the presence of nitrogen functional groups which lead to enhanced surface wettability and pseudocapacitance. ${ }^{\mathbf{1 4}}$ A clear upward trend in CV plot of C-800 (at $0 \mathrm{~V}$ ) can be observed which is due to the higher intrinsic resistivity. The CV curves of NC-800 are slightly deviated from the rectangular shape at high scan rates $\left(>50 \mathrm{mV} \mathrm{s}^{-1}\right)$ as shown in Fig. 5b. This deviation can be linked to the poor penetration/distribution of applied potential through the material pores, the inherent resistance of the electrode material, electrolyte diffusion resistance, and the contact resistance between the current collector and the active material. ${ }^{52}$ To further examine the electrochemical performances of the carbon electrodes, the galvanostatic charge/discharge (GCD) measurement was carried out within -1 to $0 \mathrm{~V}$ at a current density of $1 \mathrm{~A} \mathrm{~g}^{-1}$ (Fig. 5c). The long discharging time recorded for NC-800 sample is an indicative of a superior capacitive performance similar to the CV result. Additionally, the GCD curves for NC-800 at various current densities are shown in Fig. $5 \mathrm{~d}$ and e. Although the $I R$ drop is present at relatively high current densities, the anodic charging and cathodic discharging segments in NC-800 formed symmetric triangles, which is suggesting a fast dynamics charge-discharge process and proper capacitive characteristics. The specific capacitance $\left(C_{\mathrm{s}}\right)$ was calculated from the GCD curves using eqn (1) (Fig. 5f). The $C_{\mathrm{s}}$ of electrodes were measured as 236, 285, 263 and $248 \mathrm{~F} \mathrm{~g}^{-1}$ for NC-700, NC-800, NC-900 and C-800, respectively at a current density of $1 \mathrm{~A} \mathrm{~g}^{-1}$. The specific capacitance contributed by nickel substrate was less than $0.1 \%$. Among all studied electrodes, NC-800 sample exhibited the best capacitive behavior. Following reasons may be speculated for superior performance of NC-800. First, the $C_{\mathrm{s}}$ of NC-800 was $21 \%$ higher than NC-700 because of a significant enhancement in the surface area of NC-800 (1803 $\left.\mathrm{m}^{2} \mathrm{~g}^{-1}\right)$ as compared to NC-700 $\left(1264 \mathrm{~m}^{2} \mathrm{~g}^{-1}\right)$. A high surface area (or total pores volume) enhances the mass transport through the porous framework increasing access to the ion-accessible surface area and the number of electroactive sites. ${ }^{53,54}$ Second, the $C_{\mathrm{s}}$ slightly decreases when the annealing temperature is increased from 800 to $900{ }^{\circ} \mathrm{C}$, which is related to a decrease in the $\mathrm{N} / \mathrm{C}$ ratio and in micro/total pore volume ratio. Third, the $C_{\mathrm{s}}$ for NC-800 is $15 \%$ more than the pristine electrode (C-800), which is due to the higher BET surface area and nitrogen doping level of the former. ${ }^{53,55}$ Following pseudocapacitance reaction takes place in nitrogen-containing functional groups ${ }^{56}$

$$
\begin{gathered}
-\mathrm{CH}-\mathrm{NH}_{2}+2 \mathrm{OH}^{-} \Leftrightarrow-\mathrm{C}=\mathrm{NH}+\mathrm{H}_{2} \mathrm{O}+2 \mathrm{e}^{-} \\
-\mathrm{C}-\mathrm{NH}_{2}+2 \mathrm{OH}^{-}+2 \mathrm{H}^{+} \Leftrightarrow-\mathrm{C}-\mathrm{NHOH}+\mathrm{H}_{2} \mathrm{O}+2 \mathrm{e}^{-}
\end{gathered}
$$

The $C_{\mathrm{s}}$ of NC-800 remained as high as 270, 264, 245, 226 and $200 \mathrm{~F} \mathrm{~g}^{-1}$ at various current densities 1, 2, 5, 10 and $20 \mathrm{~A} \mathrm{~g}^{-1}$, respectively, indicating a quick charge propagation capability and facile ion transport within electrode surface.

To further understand the capacitive properties for the practical applications, the asymmetric two-electrode cell is assembled to evaluate NC-800 and C-800 electrodes in $1 \mathrm{M} \mathrm{KOH}$ and $1 \mathrm{M} \mathrm{H}_{2} \mathrm{SO}_{4}$ electrolytes. Fig. 6a shows typical quasirectangular shape in both acidic and basic electrolytes at $20 \mathrm{mV} \mathrm{s}^{-1}$. NC-800 exhibited slightly higher CV area along with a bump when compared to C-800. NC-800 displays a symmetric shape over the entire voltage range up to $200 \mathrm{mV} \mathrm{s}^{-1}$ in both acidic and basic electrolytes, indicating a good rate performance as shown in Fig. $6 \mathrm{~b}$ and c. It is noted that the deviation of $\mathrm{CV}$ curve in two-electrode cell is different from three-electrode cell which is probably due to counter electrode and potential window sweeping in three-electrode cell. Fig. 6d illustrates a symmetric triangular GCD curves for NC-800 and C-800 at a current density of $1 \mathrm{~A} \mathrm{~g}^{-1}$ in the acidic/basic electrolyte. The 

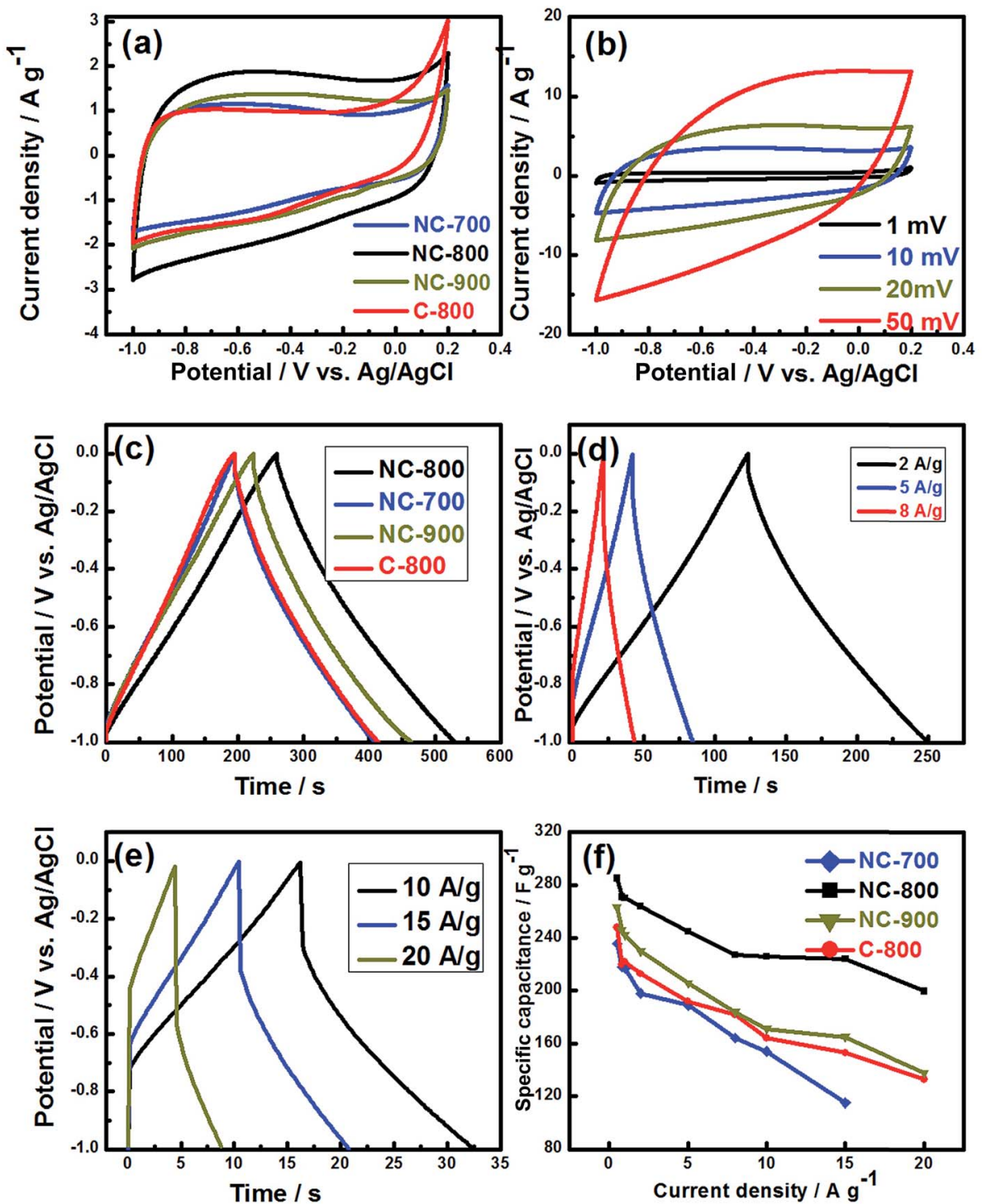

Fig. 5 Electrochemical performance of the as-prepared electrodes tested in three-electrode cell in $1 \mathrm{M} \mathrm{KOH}$ electrolyte: (a) cyclic voltammograms (CV) curves of NC-700, NC-800, NC-900 and C-800 at $5 \mathrm{mV} \mathrm{s}^{-1}$ scan rate, (b) CV curves of NC-800 at different scan rate from 1 to $50 \mathrm{mV} \mathrm{s}^{-1}$, (c) the GCD curves of as-prepared electrodes at $1 \mathrm{~A} \mathrm{~g}^{-1}$ current density, (d and e) GCD curves of NC-800 at from 2 to $20 \mathrm{Ag} \mathrm{g}^{-1}$, and (f) specific capacitance of as-prepared electrodes.

GCD curves of NC-800 at various current densities are depicted in Fig. 6e and f. Only a slight $I R$ drop has been observed at high current densities implying that the faradaic pseudocapacitance is still present in the nitrogen-doped sample. NC-800 and C-800 exhibited a capacitance of 156 and $130 \mathrm{~F} \mathrm{~g}^{-1}$ in $1 \mathrm{M} \mathrm{KOH}$ and 178 and $132 \mathrm{~F} \mathrm{~g}^{-1}$ in $1 \mathrm{M} \mathrm{H}_{2} \mathrm{SO}_{4}$ electrolyte, respectively, at $0.5 \mathrm{~A} \mathrm{~g}^{-1}$ current density (Fig. 7a). The induced $C_{\mathrm{s}}$ in NC-800 originates from improved faradaic characteristics caused by nitrogen and oxygen doped functional groups. In addition, the superior electrochemical performance the electrodes could be attributed to a unique hierarchical porous structure of the material. Similarly, Fang et al. suggested that the optimal design of hierarchical porous architecture in the electrode material can enhance the electrochemical activity for the energy storage applications where micro pores are responsible for the charge accumulation, interconnect porosity for rapid ion diffusion, and macroporosity for ion-buffering in the electrolyte. ${ }^{17,19,41,57}$ The fact that NC-800 sustains a capacitance value as high as $95 \mathrm{~F} \mathrm{~g}^{-1}$ (in $1 \mathrm{M} \mathrm{KOH}$ ) and $104 \mathrm{~F} \mathrm{~g}^{-1}$ (in $1 \mathrm{M} \mathrm{H}_{2} \mathrm{SO}_{4}$ ) at $15 \mathrm{~A} \mathrm{~g}^{-1}$ current density suggests a proper capacitive performance with a favorable reversibility. We further measured the volumetric capacitance $\left(C_{\mathrm{v}}\right)$ of $\mathrm{NC}-800$ and $\mathrm{C}-800$ (pristine) using eqn (3) and a two-electrode cell configuration. The $C_{\mathrm{v}}$ values are found to be $179,174,149$ and $128 \mathrm{~F} \mathrm{~cm}^{-3}$ for NC-800 and $150,143,114$ and $104 \mathrm{~F} \mathrm{~cm}^{-3}$ for C-800 a current density of $0.5,1,5$ and $10 \mathrm{~A} \mathrm{~g}^{-1}$, respectively. The volumetric capacitance of NC-800 was notably much higher than C-800.

The Ragone plots from the GCD experiments in a twoelectrode configuration are compared for NC-800 and C-800 in Fig. 7b. The N-doped sample displayed higher power and energy 

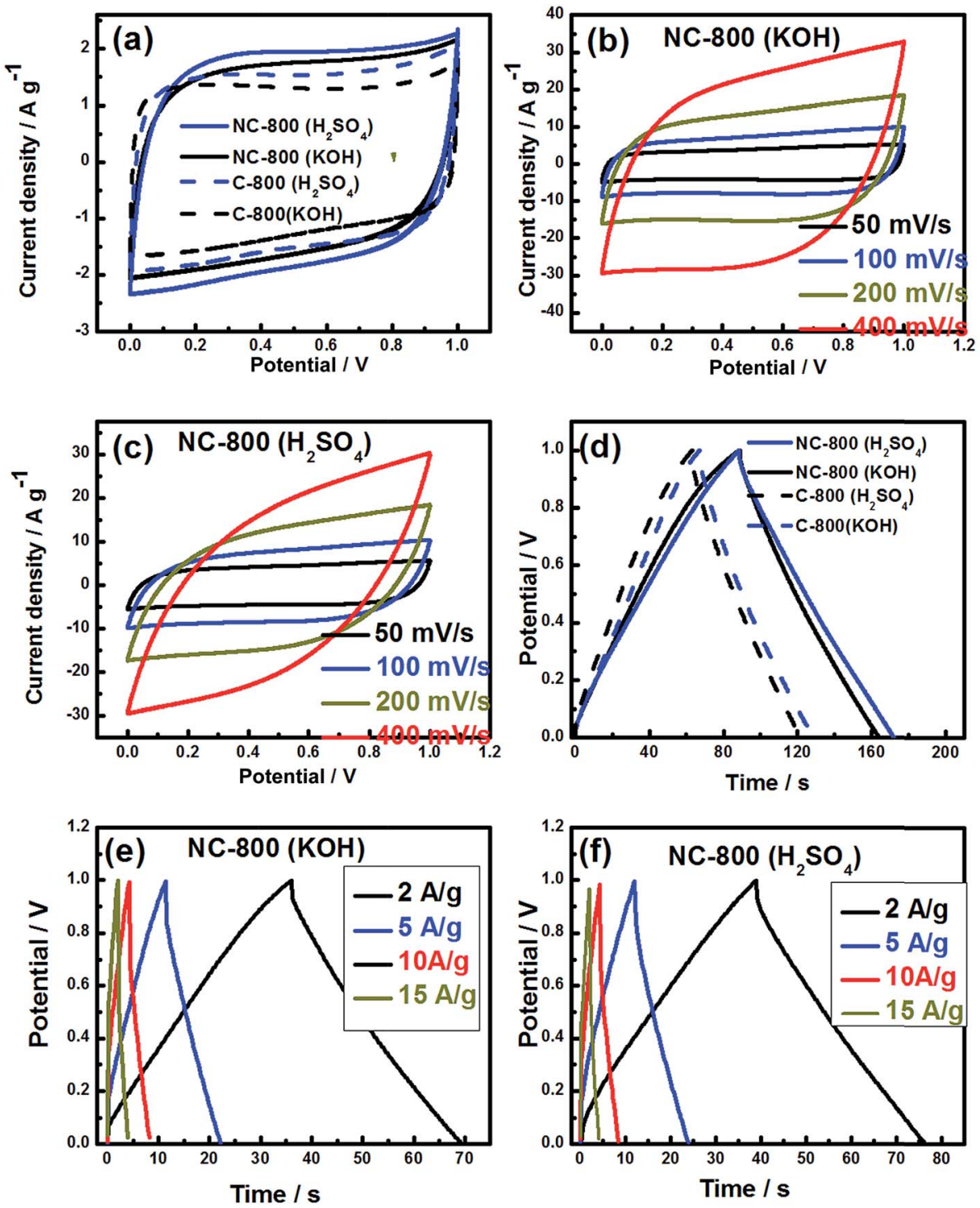

Fig. 6 Electrochemical performance of NC-800 and C-800 electrodes tested in a two-electrode cell: (a) the CV curves of NC-800 and C-800 at $20 \mathrm{mV} \mathrm{s}^{-1}$ scan rate, (b) the CV curves of NC-800 at different scan rate from 50 to $400 \mathrm{mV} \mathrm{s}^{-1}$ in $1 \mathrm{M} \mathrm{KOH}$, (c) the CV curves of NC-800 at different scan rate from 50 to $400 \mathrm{mV} \mathrm{s}^{-1}$ in $1 \mathrm{M} \mathrm{H}_{2} \mathrm{SO}_{4}$, (d) the GCD curves of $\mathrm{NC}-800$ and $\mathrm{C}-800$ at $1 \mathrm{Ag}^{-1}$ current density (e) the GCD curves of $\mathrm{NC}-800$ at different current densities from 2 to $15 \mathrm{~A} \mathrm{~g}^{-1}$ in $1 \mathrm{M} \mathrm{KOH}$, (f) the GCD curves of $\mathrm{NC}-800$ at different current densities from 2 to $15 \mathrm{~A} \mathrm{~g}{ }^{-1}$ in $1 \mathrm{M} \mathrm{H}_{2} \mathrm{SO}_{4}$.

densities than the pristine sample in both $\mathrm{KOH}$ and $\mathrm{H}_{2} \mathrm{SO}_{4}$ electrolytes. NC-800 displays (calculated from eqn (5) and (6)) an energy density of $21.6 \mathrm{~W} \mathrm{~h} \mathrm{~kg}^{-1}$ at a power density of $500 \mathrm{~W} \mathrm{~kg}^{-1}$ while C-800 exhibits an energy density of $18 \mathrm{~W} \mathrm{~h} \mathrm{~kg}^{-1}$ at a power density of $500 \mathrm{~W} \mathrm{~kg}^{-1}$ in $1 \mathrm{M} \mathrm{KOH}$ electrolyte. In $1 \mathrm{M} \mathrm{H}_{2} \mathrm{SO}_{4}$ electrolyte solution, NC-800 displays an energy density of $24.7 \mathrm{~W} \mathrm{~h} \mathrm{~kg}^{-1}$ at a power density of $500 \mathrm{~W} \mathrm{~kg}^{-1}$ while C-800 exhibits an energy density of $18.3 \mathrm{~W} \mathrm{~h} \mathrm{~kg}^{-1}$ at a power density of $500 \mathrm{~W} \mathrm{~kg}^{-1}$, which higher or comparable to the reported values for other biomass-derived carbon materials summarized in Table 3.

The Electrochemical Impedance Spectroscopy (EIS) analysis is performed in the frequency range of $0.01 \mathrm{~Hz}$ to $500 \mathrm{kHz}$ to investigate the charge-transfer resistivity and ion diffusion performance of the electrodes (Fig. 7c). Near vertical straight lines in a low frequency are an illustration of the ideal capacitive behavior. In addition, the slope of the curves at a low frequency region also called as Warburg impedance (W) is very short which is indicative of a short diffusion pathway and an efficient access of the electrolyte ions to the electrode surface. ${ }^{68}$ The $x$-axis intercept on the real axis $\left(Z^{\prime}\right)$ in the high-frequency region corresponds to ohmic resistivity $\left(R_{\mathrm{S}}\right)$ which is derived from contact resistance between the current collector and the active material. The $R_{\mathrm{S}}$ values were calculated as 2.9 and $4.1 \Omega$ in $1 \mathrm{M}$ $\mathrm{KOH}$ and 4.8 and 5.3 in $1 \mathrm{M} \mathrm{H}_{2} \mathrm{SO}_{4}$ for $\mathrm{NC}-800$ and C-800, respectively, confirming a higher contact conductivity of NC800 as compared to the pristine electrode. The Nyquist plot of both electrodes showed a semicircle in the high-frequency 

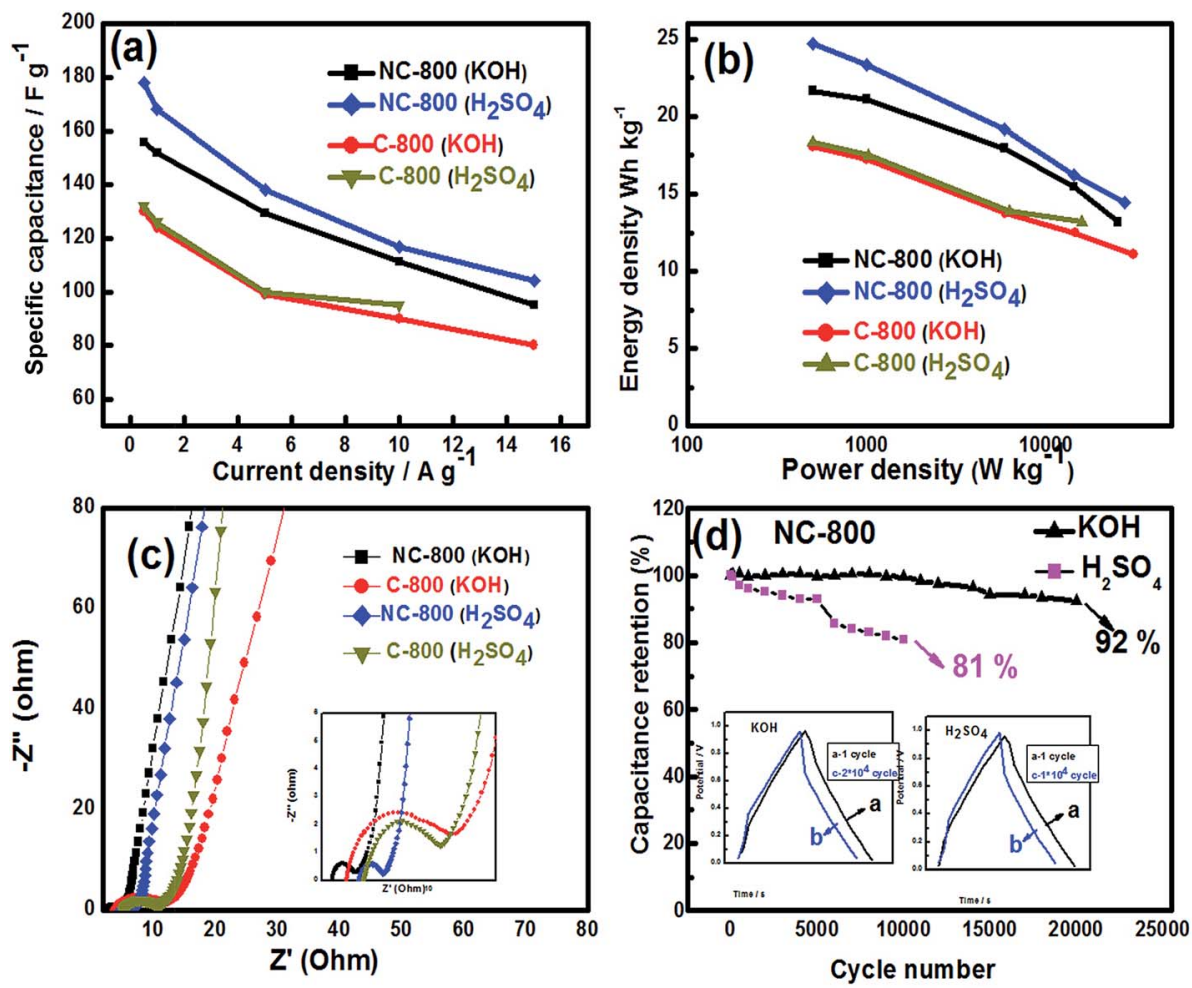

Fig. 7 In two-electrode cell (a) the specific capacitance of NC-800 and C-800 variable current densities, (b) the Ragone chart of NC-800 and C-800, (c) Nyquist plot of NC-800 and C-800 electrodes, and (d) cycling performance of NC-800 in both acidic and basic electrolytes.

Table 3 Activation method, textural properties and specific capacitance of electrodes prepared from various precursors

\begin{tabular}{|c|c|c|c|c|c|c|}
\hline Carbon precursor & Activation method & $\begin{array}{l}\text { Surface area } \\
\left(\mathrm{m}^{2} \mathrm{~g}^{-1}\right)\end{array}$ & $\begin{array}{l}\text { Capacitance } \\
\left(\mathrm{F} \mathrm{g}^{-1}\right)\end{array}$ & Electrolyte & $\begin{array}{l}\text { Measurement } \\
\text { condition }\end{array}$ & Ref. \\
\hline Lecithin & HTC/KOH & 1803 & 285 & $1 \mathrm{M} \mathrm{KOH}$ & $0.5 \mathrm{Ag} \mathrm{g}^{-1}$ & This work \\
\hline $\mathrm{N}$-Doped graphene oxide & & & 144.6 & $0.1 \mathrm{M} \mathrm{KOH}$ & $0.2 \mathrm{~A} \mathrm{~g}^{-1}$ & 59 \\
\hline Rice & $\mathrm{ZnCl}_{2}$ & 2106 & 398 & $6 \mathrm{M} \mathrm{KOH}$ & $0.2 \mathrm{~A} \mathrm{~g}^{-1}$ & 60 \\
\hline Seaweeds & Thermal & 1307 & 264 & $1 \mathrm{M} \mathrm{H}_{2} \mathrm{SO}_{4}$ & $0.2 \mathrm{~A} \mathrm{~g}^{-1}$ & 61 \\
\hline Watermelon & $\mathrm{KOH}$ & $2936-3420$ & 150.6 & $6 \mathrm{M} \mathrm{KOH}$ & $0.2 \mathrm{~A} \mathrm{~g}^{-1}$ & 64 \\
\hline Glucosamine & Hydrothermal & 200 & 56 & $1 \mathrm{M} \mathrm{H}_{2} \mathrm{SO}_{4}$ & $2 \mathrm{mV} \mathrm{s}^{-1}$ & 65 \\
\hline Fish scale & $\mathrm{KOH}$ & 2273 & 168 & $7 \mathrm{M} \mathrm{KOH}$ & $0.05 \mathrm{~A} \mathrm{~g}^{-1}$ & 66 \\
\hline Tobacco waste & Self-activation & 1104 & 170 & $6 \mathrm{M} \mathrm{KOH}$ & $0.5 \mathrm{~A} \mathrm{~g}^{-1}$ & 67 \\
\hline
\end{tabular}

range known as the charge transfer resistance $R_{\mathrm{ct}}$. The $R_{\mathrm{ct}}$ values were found to be 1.4 and $5.6 \Omega$ in $1 \mathrm{M} \mathrm{KOH}$ and 4.8 and $4.3 \Omega$ in $1 \mathrm{M} \mathrm{H}_{2} \mathrm{SO}_{4}$ for NC-800 and C-800, respectively. The small charge transfer resistance can ensure the superior ability for rapid electron transportation in the electrode surface. ${ }^{\mathbf{6 8 , 6 9}}$

In order to evaluate the cycling stability of NC-800, the GCD was carried out in $1 \mathrm{M} \mathrm{KOH}$ and $1 \mathrm{M} \mathrm{H}_{2} \mathrm{SO}_{4}$ electrolyte at $5 \mathrm{Ag}^{-1}$ in a two-cell electrode configuration as shown in Fig. 7d. The capacitive performance of NC-800 resulting in a retention of about $81.3 \%$ over 10000 continuous cycles in $1 \mathrm{M} \mathrm{H}_{2} \mathrm{SO}_{4}$ which is caused by releasing of active material from the current collector. In $1 \mathrm{M} \mathrm{KOH}$ electrolyte, the capacitance retention of NC-800 is yet $92 \%$ over 20000 cycles, reflecting a long-term stability of $\mathrm{NC}-800$ as an electrode material in the basic electrolyte.

\section{Conclusions}

This work reports a facile method for the preparation of hierarchical $\mathrm{N}$-doped porous carbons derived from farmbased renewable precursors. NC-800 sample exhibited the highest specific capacitance of $285 \mathrm{~F} \mathrm{~g}^{-1}$ at $1 \mathrm{Ag}^{-1}$ in $1 \mathrm{M} \mathrm{KOH}$ due to the collaborative effects of nitrogen functional groups, high surface area and the well-developed hierarchy of pores. Moreover NC-800 delivered a maximum energy density of $21.6 \mathrm{~W} \mathrm{~h} \mathrm{~kg}^{-1}$ and power density of $500 \mathrm{~W} \mathrm{~kg}^{-1}$. In addition, 
NC-800 electrode featured outstanding capacitance retention over 20000 cycles. The proposed strategy offers an efficient and economically reasonable utilization of lecithin to generate $\mathrm{N}$-doped carbons for energy storage applications.

\section{Conflicts of interest}

There are no conflicts to declare.

\section{Acknowledgements}

Muslum Demir thanks the Ministry of National Educational of the Republic of Turkey for his graduate fellowship.

\section{References}

1 P. Simon and Y. Gogotsi, Materials for electrochemical capacitors, Nat. Mater., 2008, 7(11), 845-854.

2 A. L. M. Reddy, S. R. Gowda, M. M. Shaijumon and P. M. Ajayan, Hybrid nanostructures for energy storage applications, Adv. Mater., 2012, 24(37), 5045-5064.

3 Y. Zhu, S. Murali, M. D. Stoller, K. Ganesh, W. Cai, P. J. Ferreira, A. Pirkle, R. M. Wallace, K. A. Cychosz and M. Thommes, Carbon-based supercapacitors produced by activation of graphene, Science, 2011, 332(6037), 1537-1541.

4 L. Sun, C. G. Tian, M. T. Li, X. Y. Meng, L. Wang, R. H. Wang, J. Yin and H. G. Fu, From coconut shell to porous graphenelike nanosheets for high-power supercapacitors, J. Mater. Chem. A, 2013, 1(21), 6462-6470.

5 L. L. Zhang and X. S. Zhao, Carbon-based materials as supercapacitor electrodes, Chem. Soc. Rev., 2009, 38(9), 2520-2531.

6 B. Fang and L. Binder, A novel carbon electrode material for highly improved EDLC performance, J. Phys. Chem. B, 2006, 110(15), 7877-7882.

7 N.-L. Wu, Nanocrystalline oxide supercapacitors, Mater. Chem. Phys., 2002, 75(1-3), 6-11.

8 K. S. Ryu, K. M. Kim, N.-G. Park, Y. J. Park and S. H. Chang, Symmetric redox supercapacitor with conducting polyaniline electrodes, J. Power Sources, 2002, 103(2), 305-309.

9 M. Alhabeb, M. Beidaghi, K. L. Van Aken, B. Dyatkin and Y. Gogotsi, High-density freestanding graphene/carbidederived carbon film electrodes for electrochemical capacitors, Carbon, 2017, 118, 642-649.

10 G. Xu, C. Zheng, Q. Zhang, J. Huang, M. Zhao, J. Nie, X. Wang and F. Wei, Binder-free activated carbon/carbon nanotube paper electrodes for use in supercapacitors, Nano Res., 2011, 4(9), 870-881.

11 D. Torregrossa and M. Paolone, Modelling of current and temperature effects on supercapacitors ageing. Part I: review of driving phenomenology, J Energy Storage, 2016, 5, 85-94.

12 L. L. Liu, Z. Q. Niu and J. Chen, Unconventional supercapacitors from nanocarbon-based electrode materials to device configurations, Chem. Soc. Rev., 2016, 45(15), 4340-4363.
13 B. Fang, A. Bonakdarpour, M.-S. Kim, J. H. Kim, D. P. Wilkinson and J.-S. Yu, Multimodal porous carbon as a highly efficient electrode material in an electric double layer capacitor, Microporous Mesoporous Mater., 2013, 182, 1-7.

14 Y. H. Zhao, M. X. Liu, X. X. Deng, L. Miao, P. K. Tripathi, X. M. Ma, D. Z. Zhu, Z. J. Xu, Z. X. Hao and L. H. Gan, Nitrogen-functionalized microporous carbon nanoparticles for high performance supercapacitor electrode, Electrochim. Acta, 2015, 153, 448-455.

15 G. Wang, J. Zhang, S. Kuang, J. Zhou, W. Xing and S. Zhuo, Nitrogen-doped hierarchical porous carbon as an efficient electrode material for supercapacitors, Electrochim. Acta, 2015, 153, 273-279.

16 D. Y. Zhang, Y. Hao, L. W. Zheng, Y. Ma, H. X. Feng and H. M. Luo, Nitrogen and sulfur co-doped ordered mesoporous carbon with enhanced electrochemical capacitance performance, J. Mater. Chem. A, 2013, 1(26), 7584-7591.

17 S. Dutta, A. Bhaumik and K. C.-W. Wu, Hierarchically porous carbon derived from polymers and biomass: effect of interconnected pores on energy applications, Energy Environ. Sci., 2014, 7(11), 3574-3592.

18 Y. S. Yun, C. Im, H. H. Park, I. Hwang, Y. Tak and H. J. Jin, Hierarchically porous carbon nanofibers containing numerous heteroatoms for supercapacitors, J. Power Sources, 2013, 234, 285-291.

19 B. Fang, J. H. Kim, M.-S. Kim and J.-S. Yu, Hierarchical Nanostructured Carbons with Meso-Macroporosity: Design, Characterization, and Applications, Acc. Chem. Res., 2013, 46(7), 1397-1406.

20 H. B. Feng, M. T. Zheng, H. W. Dong, Y. Xiao, H. Hu, Z. X. Sun, C. Long, Y. J. Cai, X. Zhao, H. R. Zhang, B. F. Lei and Y. L. Liu, Three-dimensional honeycomb-like hierarchically structured carbon for high-performance supercapacitors derived from high-ash-content sewage sludge, J. Mater. Chem. A, 2015, 3(29), 15225-15234.

21 H. Jiang, P. S. Lee and C. Z. Li, 3D carbon based nanostructures for advanced supercapacitors, Energy Environ. Sci., 2013, 6(1), 41-53.

22 B. Fang, J. H. Kim, M.-S. Kim, A. Bonakdarpour, A. Lam, D. P. Wilkinson and J.-S. Yu, Fabrication of hollow core carbon spheres with hierarchical nanoarchitecture for ultrahigh electrical charge storage, J. Mater. Chem., 2012, 22(36), 19031-19038.

23 X. Wen, D. Zhang, T. Yan, J. Zhang and L. Shi, Threedimensional graphene-based hierarchically porous carbon composites prepared by a dual-template strategy for capacitive deionization, J. Mater. Chem. A, 2013, 1(39), 12334-12344.

24 K. Xie, X. Qin, X. Wang, Y. Wang, H. Tao, Q. Wu, L. Yang and Z. Hu, Carbon nanocages as supercapacitor electrode materials, Adv. Mater., 2012, 24(3), 347-352.

25 L. Qie, W. M. Chen, H. H. Xu, X. Q. Xiong, Y. Jiang, F. Zou, X. L. Hu, Y. Xin, Z. L. Zhang and Y. H. Huang, Synthesis of functionalized 3D hierarchical porous carbon for highperformance supercapacitors, Energy Environ. Sci., 2013, 6(8), 2497-2504. 
26 L. Wei, M. Sevilla, A. B. Fuertes, R. Mokaya and G. Yushin, Polypyrrole-Derived Activated Carbons for HighPerformance Electrical Double-Layer Capacitors with Ionic Liquid Electrolyte, Adv. Funct. Mater., 2012, 22(4), 827-834.

27 L. J. Xie, G. H. Sun, F. Y. Su, X. Q. Guo, Q. Q. Kong, X. M. Li, X. H. Huang, L. Wan, W. Song, K. X. Li, C. X. Lv and C. M. Chen, Hierarchical porous carbon microtubes derived from willow catkins for supercapacitor applications, J. Mater. Chem. A, 2016, 4(5), 1637-1646.

28 A. Bello, N. Manyala, F. Barzegar, A. A. Khaleed, D. Y. Momodu and J. K. Dangbegnon, Renewable pine cone biomass derived carbon materials for supercapacitor application, RSC Adv., 2016, 6(3), 1800-1809.

29 D. Saha, Y. Li, Z. Bi, J. Chen, J. K. Keum, D. K. Hensley, H. A. Grappe, H. M. Meyer III, S. Dai and M. P. Paranthaman, Studies on supercapacitor electrode material from activated lignin-derived mesoporous carbon, Langmuir, 2014, 30(3), 900-910.

30 M. Demir, Z. Kahveci, B. Aksoy, N. K. Palapati, A. Subramanian, H. T. Cullinan, H. M. El-Kaderi, C. T. Harris and R. B. Gupta, Graphitic bio-carbon from metal-catalyzed hydrothermal carbonization of lignin, Ind. Eng. Chem. Res., 2015.

31 N. K. R. Palapati, M. Demir, C. T. Harris, A. Subramanian and R. B. Gupta, Enhancing the electronic conductivity of Lignin-sourced, sub-micron carbon particles, IEEE Nanotechnol. Mater. Devices Conf., 2015, 2015, 1-2.

32 H. Zhu, X. Wang, F. Yang and X. Yang, Promising Carbons for Supercapacitors Derived from Fungi, Adv. Mater., 2011, 23(24), 2745-2748.

33 D. Liu, S. Yu, Y. L. Shen, H. Chen, Z. H. Shen, S. Y. Zhao, S. Y. Fu, Y. M. Yu and B. F. Bao, Polyaniline Coated Boron Doped Biomass Derived Porous Carbon Composites for Supercapacitor Electrode Materials, Ind. Eng. Chem. Res., 2015, 54(50), 12570-12579.

34 B. F. Szuhaj, Lecithins: sources, manufacture \& uses, The American Oil Chemists Society, 1989, vol. 12.

35 E. Nyankson, M. Demir, M. Gonen and R. B. Gupta, Interfacially Active Hydroxylated Soybean Lecithin Dispersant for Crude Oil Spill Remediation, ACS Sustainable Chem. Eng., 2016, 4(4), 2056-2067.

36 L. L. Zhang, H. H. Li, Y. H. Shi, C. Y. Fan, X. L. Wu, H. F. Wang, H. Z. Sun and J. P. Zhang, A Novel Layered Sedimentaly Rocks Structure of the Oxygen-Enriched Carbon for Ultrahigh-Rate-Performance Supercapacitors, ACS Appl. Mater. Interfaces, 2016, 8(6), 4233-4241.

37 Q. X. Xie, R. R. Bao, A. R. Zheng, Y. F. Zhang, S. H. Wu, C. Xie and P. Zhao, Sustainable Low-Cost Green Electrodes with High Volumetric Capacitance for Aqueous Symmetric Supercapacitors with High Energy Density, ACS Sustainable Chem. Eng., 2016, 4(3), 1422-1430.

38 A. B. Fuertes Arias, G. Ferrero and M. Sevilla Solís, Commentary: Methods of calculating the volumetric performance of a supercapacitor, Energy Storage Mater., 2016.

39 G. Ma, Q. Yang, K. Sun, H. Peng, F. Ran, X. Zhao and Z. Lei, Nitrogen-doped porous carbon derived from biomass waste for high-performance supercapacitor, Bioresour. Technol, 2015, 197, 137-142.

40 J. Kuligowski, G. Quintás, F. Esteve-Turrillas, S. Garrigues and M. De la Guardia, On-line gel permeation chromatographyattenuated total reflectance-Fourier transform infrared determination of lecithin and soybean oil in dietary supplements, J. Chromatogr. A, 2008, 1185(1), 71-77.

41 M. Sevilla and R. Mokaya, Energy storage applications of activated carbons: supercapacitors and hydrogen storage, Energy Environ. Sci., 2014, 7(4), 1250-1280.

42 Y. M. Tan, C. F. Xu, G. X. Chen, Z. H. Liu, M. Ma, Q. J. Xie, N. F. Zheng and S. Z. Yao, Synthesis of Ultrathin NitrogenDoped Graphitic Carbon Nanocages as Advanced Electrode Materials for Supercapacitor, ACS Appl. Mater. Interfaces, 2013, 5(6), 2241-2248.

43 L. Zhang, Z. Liu, G. Cui and L. Chen, Biomass-derived materials for electrochemical energy storages, Prog. Polym. Sci., 2015, 43, 136-164.

44 R. T. Wang, P. Y. Wang, X. B. Yan, J. W. Lang, C. Peng and Q. J. Xue, Promising Porous Carbon Derived from Celtuce Leaves with Outstanding Supercapacitance and $\mathrm{CO} 2$ Capture Performance, ACS Appl. Mater. Interfaces, 2012, 4(11), 5800-5806.

45 S. J. He, H. Q. Hou and W. Chen, 3D porous and ultralight carbon hybrid nanostructure fabricated from carbon foam covered by monolayer of nitrogen-doped carbon nanotubes for high performance supercapacitors, J. Power Sources, 2015, 280, 678-686.

46 K. Wang, N. Zhao, S. W. Lei, R. Yan, X. D. Tian, J. Z. Wang, Y. Song, D. F. Xu, Q. G. Guo and L. Liu, Promising biomass-based activated carbons derived from willow catkins for high performance supercapacitors, Electrochim. Acta, 2015, 166, 1-11.

47 Y. J. Hu, X. Tong, H. Zhuo, L. X. Zhong, X. W. Peng, S. Wang and R. C. Sun, 3D hierarchical porous N-doped carbon aerogel from renewable cellulose: an attractive carbon for high-performance supercapacitor electrodes and $\mathrm{CO} 2$ adsorption, RSC Adv., 2016, 6(19), 15788-15795.

48 W. H. Yu, H. L. Wang, S. Liu, N. Mao, X. Liu, J. Shi, W. Liu, S. G. Chen and X. Wang, N,O-Codoped hierarchical porous carbons derived from algae for high-capacity supercapacitors and battery anodes, J. Mater. Chem. A, 2016, 4(16), 5973-5983.

49 S. Gharehkhani, S. F. S. Shirazi, S. P. Jahromi, M. Sookhakian, S. Baradaran, H. Yarmand, A. A. Oshkour, S. N. Kazi and W. J. Basirun, Spongy nitrogen-doped activated carbonaceous hybrid derived from biomass material/graphene oxide for supercapacitor electrodes, $R S C$ $A d v .$, 2015, 5(51), 40505-40513.

50 F. Gao, G. H. Shao, J. Y. Qu, S. Y. Lv, Y. Q. Li and M. B. Wu, Tailoring of porous and nitrogen-rich carbons derived from hydrochar for high-performance supercapacitor electrodes, Electrochim. Acta, 2015, 155, 201-208.

51 W. H. Lee and J. H. Moon, Monodispersed N-Doped Carbon Nanospheres for Supercapacitor Application, ACS Appl. Mater. Interfaces, 2014, 6(16), 13968-13976.

52 S. Bose, T. Kuila, A. K. Mishra, R. Rajasekar, N. H. Kim and J. H. Lee, Carbon-based nanostructured materials and their 
composites as supercapacitor electrodes, J. Mater. Chem., 2012, 22(3), 767-784.

53 C. P. Ruan, K. L. Ai and L. H. Lu, Biomass-derived carbon materials for high-performance supercapacitor electrodes, RSC Adv., 2014, 4(58), 30887-30895.

54 Y. M. Ren, Q. Xu, J. M. Zhang, H. X. Yang, B. Wang, D. Y. Yang, J. H. Hu and Z. M. Liu, Functionalization of Biomass Carbonaceous Aerogels: Selective Preparation of MnO2@CA Composites for Supercapacitors, ACS Appl. Mater. Interfaces, 2014, 6(12), 9689-9697.

55 E. J. Ra, E. Raymundo-Piñero, Y. H. Lee and F. Béguin, High power supercapacitors using polyacrylonitrilebased carbon nanofiber paper, Carbon, 2009, 47(13), 2984-2992.

56 X. Wei, X. Jiang, J. Wei and S. Gao, Functional Groups and Pore Size Distribution do Matter to Hierarchically Porous Carbons as High-Rate-Performance Supercapacitors, Chem. Mater., 2015.

57 S.-Q. Fan, B. Fang, J. H. Kim, J.-J. Kim, J.-S. Yu and J. Ko, Hierarchical nanostructured spherical carbon with hollow core/mesoporous shell as a highly efficient counter electrode in CdSe quantum-dot-sensitized solar cells, Appl. Phys. Lett., 2010, 96(6), 063501.

58 Z. Li, L. Zhang, B. S. Amirkhiz, X. H. Tan, Z. W. Xu, H. L. Wang, B. C. Olsen, C. M. B. Holt and D. Mitlin, Carbonized Chicken Eggshell Membranes with 3D Architectures as High-Performance Electrode Materials for Supercapacitors, Adv. Energy Mater., 2012, 2(4), 431-437.

59 B. J. Jiang, C. G. Tian, L. Wang, L. Sun, C. Chen, X. Z. Nong, Y. J. Qiao and H. G. Fu, Highly concentrated, stable nitrogendoped graphene for supercapacitors: Simultaneous doping and reduction, Appl. Surf. Sci., 2012, 258(8), 3438-3443.

60 S. Y. Gao, Y. L. Chen, H. Fan, X. J. Wei, C. G. Hu, H. X. Luo and L. T. Qu, Large scale production of biomass-derived Ndoped porous carbon spheres for oxygen reduction and supercapacitors, J. Mater. Chem. A, 2014, 2(10), 3317-3324.

61 E. Raymundo-Piñero, M. Cadek and F. Béguin, Tuning carbon materials for supercapacitors by direct pyrolysis of seaweeds, Adv. Funct. Mater., 2009, 19(7), 1032-1039.
62 J. Y. Tian, Z. M. Liu, Z. H. Li, W. G. Wang and H. Y. Zhang, Hierarchical S-doped porous carbon derived from byproduct lignin for high-performance supercapacitors, $R S C$ Adv., 2017, 7(20), 12089-12097.

63 N. Subramanian and B. Viswanathan, Nitrogen- and oxygencontaining activated carbons from sucrose for electrochemical supercapacitor applications, $R S C A d v$, 2015, 5(77), 63000-63011.

64 Y. M. Ren, J. M. Zhang, Q. Xu, Z. M. Chen, D. Y. Yang, B. Wang and Z. Jiang, Biomass-derived three-dimensional porous $\mathrm{N}$-doped carbonaceous aerogel for efficient supercapacitor electrodes, RSC Adv., 2014, 4(45), 2341223419.

65 M. Sevilla, L. H. Yu, L. Zhao, C. O. Ania and M. M. Titiricic, Surface Modification of CNTs with N-Doped Carbon: An Effective Way of Enhancing Their Performance in Supercapacitors, ACS Sustainable Chem. Eng., 2014, 2(4), 1049-1055.

66 W. Chen, H. Zhang, Y. Huang and W. Wang, A fish scale based hierarchical lamellar porous carbon material obtained using a natural template for high performance electrochemical capacitors, J. Mater. Chem., 2010, 20(23), 4773-4775.

67 Y. Sha, J. Lou, S. Bai, D. Wu, B. Liu and Y. Ling, Facile preparation of nitrogen-doped porous carbon from waste tobacco by a simple pre-treatment process and their application in electrochemical capacitor and $\mathrm{CO} 2$ capture, Mater. Res. Bull., 2015, 64, 327-332.

68 Y. Q. Zhao, M. Lu, P. Y. Tao, Y. J. Zhang, X. T. Gong, Z. Yang, G. Q. Zhang and H. L. Li, Hierarchically porous and heteroatom doped carbon derived from tobacco rods for supercapacitors, J. Power Sources, 2016, 307, 391-400.

69 H. C. Hsu, C. H. Wang, Y. C. Chang, J. H. Hu, B. Y. Yao and C. Y. Lin, Graphene oxides and carbon nanotubes embedded in polyacrylonitrile-based carbon nanofibers used as electrodes for supercapacitor, J. Phys. Chem. Solids, 2015, 85, 62-68. 